\title{
A study of occurrence of non-alcoholic steatohepatitis in children with obesity and overweight
}

\author{
Sharanagouda Patil ${ }^{1}$, Kumar Angadi ${ }^{2}$, Meghana Somasundara ${ }^{3}$ \\ From ${ }^{1}$ Professor and HOD, ${ }^{2}$ Associate Professor, ${ }^{3}$ Post Graduate, Department of Paediatrics, Mahadevappa Rampure Medical College, Kalaburagi, \\ Karnataka, India
}

\begin{abstract}
Background: Non-alcoholic fatty liver disease (NAFLD) is the most common chronic liver disease in children and its increasing prevalence is associated with concomitant rise in obesity. Anthropometric measurements and non-invasive tests (liver function tests and USG abdomen) help in early recognition of non-alcoholic steatohepatitis (NASH) and reduce consequent morbidity and mortality. Aim: This study aims to study the occurrence of NASH in obese and overweight children and to derive the correlation of NASH with clinical and biochemical parameters in overweight and obese children. Methods: This hospital-based prospective study included children (age $\leq 18$ years) who met the inclusion criteria. Diagnosis of NASH was based on USG abdomen. Measurements included anthropometry, ultrasonography, fasting glucose, alanine aminotransferase (ALT), lipid profile and additional parameters of blood pressure, fasting insulin, and homeostatic model assessment of insulin resistance (HOMA-IR). The variables were compared between children with and without NASH. Results: A total of 146 patients (female: 51.4\%, male: $48.6 \%$ ) were enrolled in the study. The most common age group affected was $11-18$ years (50.7\%) followed by $6-10$ years $(43.2 \%)$ and $<5$ years $(6.2 \%)$. The occurrence of NASH in the study group was $63 \%$ of obese and overweight children. Mean weight, body mass index (BMI), waist circumference, waist-hip ratio, blood pressure (BP), serum glutamic-pyruvic transaminase (SGPT), fasting insulin level, and HOMA-IR were significantly higher in children with NASH. There was a significant association between SGPT and NASH. Elevated SGPT of $79.3 \%$ and $1.9 \%$ was observed among the subjects with and without NASH, respectively. Conclusion: Anthropometric indices and biochemical parameters were more elevated in NASH group showing its direct correlation with hepatic steatosis.
\end{abstract}

Key words: Metabolic syndrome, Nash, Non-invasive tests, Obesity

A mong the chronic liver diseases in children, non-alcoholic fatty liver disease (NAFLD) is the most common one and is prevalent in overweight or obese children [1]. It can range from fatty liver alone to a triad of fatty infiltration, inflammation, and fibrosis, termed non-alcoholic steatohepatitis (NASH).

The best diagnostic method for NAFLD is a liver biopsy, but it is difficult to perform in the pediatric obesity clinic due to cost, complications, and ethical considerations [2]. Ultrasonography (USG) is the most widely used method for NASH screening. The quantitative severity of hepatic steatosis measured by USG, correlated with the histological degree of steatosis on liver biopsy [3].

Waist circumference directly reflects abdominal fat and is closely related to the cardiovascular and metabolic

\section{Access this article online}

Received - 14 June 2021

Initial Review - 28 June 2021

Accepted - 18 August 2021

DOI: 10.32677/IJCH.2021.v08.i09.3018 complications of obesity [4-6]. Abdominal adiposity induces insulin resistance and free fatty acid accumulation through lipolysis [7]. The increased substrate for hepatic lipogenesis and relative hyperinsulinemia accelerates liver fat storage, leading to NASH $[8,9]$. The screening alanine transaminase (ALT) for elevation in today's youth (SAFETY) study recently reported that among otherwise healthy children, the $95^{\text {th }}$ percentile for ALT is $\sim 26 \mathrm{U} / \mathrm{L}$ for boys and $\sim 23 \mathrm{U} / \mathrm{L}$ for girls, suggesting much lower ALT thresholds should be used to initially screen for chronic liver disease in children [10]. Children with NASH have a high prevalence of concomitant metabolic syndrome, increased risk for developing type 2 diabetes, and progression to end-stage liver disease [11]. The risk factors for NASH include obesity, diabetes, insulin resistance (IR), and hypertriglyceridemia [12].

In spite of the availability of noninvasive tests such as liver function tests and USG abdomen that help in early recognition

\footnotetext{
Correspondence to: Dr. Kumar Angadi, Associate Professor, Department of Paediatrics, Mahadevappa Rampure Medical College, Consultant Paediatric and Adolescent Health Endocrinologist, Basaveshwar Teaching and General Hospital, Kalaburagi - 585101, Karnataka, India. E-mail: drkumarangadi@gmail.com

(C) 2021 Creative Commons Attribution-NonCommercial 4.0 International License (CC BY-NC-ND 4.0).
} 
Table 1: Mean anthropometry distribution

\begin{tabular}{lc}
\hline Variables & Mean \pm Standard deviation \\
\hline Age & $10.5 \pm 3.04$ \\
Height $(\mathrm{cm})$ & $139.59 \pm 16.07$ \\
Weight $(\mathrm{kg})$ & $52.23 \pm 16.45$ \\
Body mass index $\left(\mathrm{kg} / \mathrm{m}^{2}\right)$ & $26.19 \pm 3.79$ \\
Waist circumference $(\mathrm{cm})$ & $81.74 \pm 10.27$ \\
Hip circumference & $87.88 \pm 11.07$ \\
Waist-hip ratio & $0.93 \pm 0.04$ \\
Waist-height ratio & $0.58 \pm 0.06$ \\
Systolic blood pressure & $123.83 \pm 11.86$ \\
Diastolic blood pressure & $77.48 \pm 8.88$ \\
\hline
\end{tabular}

of NASH, there is a lack of data from Indian studies. The current study was undertaken to know the magnitude of disease burden and clinical course in Indian children.

\section{MATERIALS AND METHODS}

The present study was carried out in the Department of Pediatrics, Mahadevappa Rampure Medical College, Kalaburagi. Patient attenders were informed about the purpose of study and written consent was taken before initiation of the study. Ethical clearance was obtained by the ethical clearance committee of the institution. The study included the study of occurrence of NASH in children with obesity and overweight during the period from October 2018 to April 2020.

The inclusion criteria were children $<18$ years of age of either sex with obesity $\left(\mathrm{BMI}>95^{\text {th }}\right.$ percentile) or overweight (BMI $>85^{\text {th }}$ percentile but $<95^{\text {th }}$ percentile) according to revised Indian Academy of Pediatrics (IAP) growth chart. The exclusion criteria were obesity caused by endocrine or genetic disorders, and those with previously diagnosed diabetes mellitus or primary liver disorders were excluded from the study.

Anthropometric and laboratory assessments were as follows: BMI was calculated as weight $(\mathrm{kg}) /$ height $^{2}\left(\mathrm{~m}^{2}\right)$. Waist circumference was measured at the midpoint between the inferior border of the rib cage and the superior aspect of the iliac crest at the end of normal expiration. Hip circumference was measured at the level of the greater trochanter. The waist-to-height ratio (WHtR) was calculated as waist circumference $(\mathrm{cm})$ divided by height $(\mathrm{cm})$. The waist-to-hip ratio (WHR) was calculated as waist circumference $(\mathrm{cm})$ divided by hip circumference $(\mathrm{cm})$. Waist circumference was $>90^{\text {th }}$ percentile for age and gender [13]. WHR was considered to be high if $>0.95$ (boys) and $>0.85$ (girls) [14]. WHtR not only incorporates waist circumference as a measure of abdominal adiposity but also adjusts for an individual's size. It is an age-independent index and does not necessitate age-specific diagnostic references. NASH is higher in obese male children with a waist circumference $>90^{\text {th }}$ percentile and a WHtR $>0.56$ [15]. Hypertension was diagnosed at systolic $\mathrm{BP} \geq 130 \mathrm{mmHg}$ and/or diastolic $\mathrm{BP} \geq 85 \mathrm{mmHg}$ [16]. Metabolic syndrome in adolescents was diagnosed using the International Diabetes Federation criteria [16]. Elevated ALT
Table 2: Clinical, demographic, and anthropometric parameters of children

\begin{tabular}{|c|c|c|c|}
\hline Variables & $\begin{array}{l}\text { Subgroups of } \\
\text { the variables }\end{array}$ & Count & Percentage \\
\hline \multirow[t]{4}{*}{ Age } & $<5$ years & 9 & 6.2 \\
\hline & $6-10$ years & 63 & 43.2 \\
\hline & $11-15$ years & 66 & 45.2 \\
\hline & $>15$ years & 8 & 5.5 \\
\hline \multirow[t]{2}{*}{ Sex } & Female & 75 & 51.40 \\
\hline & Male & 71 & 48.60 \\
\hline \multirow[t]{2}{*}{ Acanthosis nigricans } & Absent & 16 & 11.00 \\
\hline & Present & 130 & 89.00 \\
\hline \multirow[t]{2}{*}{ BMI percentile } & Obese & 133 & 91.10 \\
\hline & Overweight & 13 & 8.90 \\
\hline \multirow{2}{*}{$\begin{array}{l}\text { Waist circumference } \\
\text { percentile }\end{array}$} & $>95^{\text {th }}$ & 52 & 35.60 \\
\hline & $90-95^{\text {th }}$ & 74 & 50.7 \\
\hline \multirow[t]{2}{*}{ WHR distribution } & Females $>0.85$ & 60 & 81.10 \\
\hline & Males $>0.95$ & 40 & 56.30 \\
\hline \multirow[t]{2}{*}{ Waist-height ratio } & $<0.56$ & 48 & 32.9 \\
\hline & $>0.56$ & 98 & 67.1 \\
\hline \multirow[t]{2}{*}{ SBP and DBP distribution } & $\mathrm{SBP}>130$ & 52 & 35.60 \\
\hline & $\mathrm{DBP}>85$ & 51 & 34.90 \\
\hline \multirow{4}{*}{$\begin{array}{l}\text { Fatty liver on } \\
\text { ultrasonography (USG) }\end{array}$} & Absent & 54 & 37.00 \\
\hline & Grade 1 & 68 & 46.60 \\
\hline & Grade 2 & 23 & 15.80 \\
\hline & Grade 3 & 1 & 0.70 \\
\hline \multirow[t]{2}{*}{ SGPT } & Increased & 74 & 50.7 \\
\hline & Normal & 72 & 49.3 \\
\hline \multirow[t]{4}{*}{ Lipid profile distribution } & $\begin{array}{l}\text { Total count } \\
>200\end{array}$ & 7 & 4.80 \\
\hline & $\begin{array}{l}\text { Triglycerides } \\
>150\end{array}$ & 34 & 23.30 \\
\hline & $\begin{array}{l}\text { High-density } \\
\text { lipoprotein } \\
(\text { HDL })>40\end{array}$ & 76 & 52.10 \\
\hline & $\begin{array}{l}\text { Low-density } \\
\text { lipoprotein } \\
(\mathrm{LDL})>130\end{array}$ & 6 & 4.10 \\
\hline $\begin{array}{l}\text { FBG, GTT } 2 \text { h, fasting } \\
\text { insulin, and HOMA-IR } \\
\text { distribution }\end{array}$ & $<100$ & 122 & 83.60 \\
\hline $\begin{array}{l}\text { Fasting blood glucose } \\
\text { (FBG) }\end{array}$ & $>100-<126$ & 24 & 16.40 \\
\hline \multirow{2}{*}{$\begin{array}{l}\text { Glucose tolerance test } \\
\text { (GTT) }\end{array}$} & $2 \mathrm{~h}<140$ & 142 & 97.30 \\
\hline & $>140$ & 4 & 2.70 \\
\hline \multirow[t]{2}{*}{ Fasting insulin } & $<20$ & 91 & 62.30 \\
\hline & $>20$ & 55 & 37.70 \\
\hline \multirow[t]{2}{*}{ HOMA-IR } & $\geq 3.2$ & 96 & 65.8 \\
\hline & $<3.2$ & 50 & 34.2 \\
\hline
\end{tabular}

BMI: Body mass index, WHR: Waist-hip ratio, SBP: Systolic blood pressure, DBP: Diastolic blood pressure, SGPT: Serum glutamic-pyruvic transaminase, HOMA-IR: Homeostatic model assessment of insulin resistance

was defined as $>26 \mathrm{U} / 1$ for boys and $>23 \mathrm{U} / 1$ for girls [17]. Revised IAP growth charts 2015 were used to define obese $\left(\mathrm{BMI}>95^{\text {th }}\right.$ percentile) or overweight $\left(\mathrm{BMI}>85^{\text {th }}\right.$ percentile 
and $<95^{\text {th }}$ percentile). Fasting and $2 \mathrm{~h}$ blood glucose were considered elevated if $\geq 100$ and $140 \mathrm{mg} / \mathrm{dl}$, respectively [18], and HOMA-IR (HOMA-IR $=$ fasting insulin $(\mu \mathrm{U} / \mathrm{mL}) \times$ fasting glucose $(\mathrm{mmol} / \mathrm{L}) / 22.5)$ was considered high if $\geq 3.2$ [19]. Triglyceride (TG) was considered high if $\geq 150 \mathrm{mg} / \mathrm{dl}$; highdensity lipoprotein (HDL) was considered low if $<40 \mathrm{mg} / \mathrm{dl}$, total count (TC) and low-density lipoprotein (LDL) cholesterol were considered elevated if $>200$ and $130 \mathrm{mg} / \mathrm{dl}$, respectively [20]. Acanthosis nigricans over the neck was classified as absent, mild (if visible on close visual inspection and limited to the base of skull), and moderate to severe (if extending to lateral margins of the neck or further anteriorly) [21].

All the included patients were assessed by a single sonographer following not $<8 \mathrm{~h}$ fasting using FFsonic UF-4100 apparatus with abdominal; convex linear probe $3.5 \mathrm{MHz}$. Longitudinal, subcostal, and oblique scans were performed. The liver size and echo pattern were evaluated. Liver echo pattern was graded as follows [22]: Grade 1 (mild): A slightly diffuse increase in fine echoes in the hepatic parenchyma with normal visualization of the diaphragm and intrahepatic vessel borders. Grade 2 (moderate): A moderate diffuse increase in fine echoes with slightly impaired visualization of the intrahepatic vessels and diaphragm. Grade 3 (marked): A marked increase in fine echoes with poor or no visualization of the intrahepatic vessel borders, diaphragm, and posterior portion of the right lobe of the liver.

Statistical analysis: Data were analyzed by IBM SPSS 20.0 software. For qualitative data analysis, we applied Chi-square test, Student's $t$-test, and ANOVA test were used for quantitative data analysis. $P<0.05$ was considered as statistically significant.

The etiological evaluation of 146 children was done by detailed history, physical examination, anthropometry, BP measurement, and routine investigations including complete blood count (CBC), liver function tests (LFTs), USG, lipid profile, oral glucose tolerance test (OGTT), fasting insulin levels, and HOMA-IR were performed. Weight and BMI of children were assessed by revised IAP growth chart 2015 .

\section{RESULTS}

A total of 146 children (female: $51.4 \%$, male: $48.6 \%$ ) who met the inclusion criteria were included in the study. The clinical, demographic, and anthropometric distributions of the study population are detailed in Tables 1 and 2 .

Table 3: Comparison among obese and overweight children with and without NASH

\begin{tabular}{|c|c|c|c|c|c|c|c|}
\hline \multirow[t]{3}{*}{ Variables } & \multicolumn{6}{|c|}{ NASH } & \multirow[t]{3}{*}{$P$ value } \\
\hline & \multicolumn{2}{|c|}{ No NASH } & \multicolumn{2}{|c|}{ Mild NASH } & \multicolumn{2}{|c|}{ Moderate NASH } & \\
\hline & Mean & SD & Mean & SD & Mean & SD & \\
\hline Age & 9.67 & 2.9 & 11.03 & 3.04 & 10.87 & 3.05 & $0.038^{*}$ \\
\hline Height (cm) & 136.87 & 16.01 & 140.81 & 16.58 & 142.26 & 14.45 & 0.275 \\
\hline Weight (kg) & 47.23 & 13.96 & 52.61 & 16.58 & 62.42 & 17 & $0.001 *$ \\
\hline BMI (kg/sq.m) & 24.73 & 3.19 & 25.93 & 3.03 & 30.19 & 4.29 & $<0.001^{*}$ \\
\hline Waist circumference $(\mathrm{cm})$ & 78.87 & 10.21 & 82.68 & 10.14 & 85.52 & 9.39 & $0.017^{*}$ \\
\hline Hip circumference & 88 & 12.28 & 87.1 & 10.5 & 89.79 & 9.89 & 0.592 \\
\hline Waist-hip ratio & 0.89 & 0.05 & 0.95 & 0.03 & 0.95 & 0.03 & $<0.001 *$ \\
\hline Waist-height ratio & 0.57 & 0.05 & 0.58 & 0.05 & 0.6 & 0.06 & 0.149 \\
\hline $\mathrm{HB}(\mathrm{g} / \mathrm{dl})$ & 12.66 & 1.52 & 13.21 & 1.39 & 12.8 & 1.15 & 0.091 \\
\hline SGPT (IU/L) & 17.87 & 3.92 & 34.81 & 14.94 & 47.11 & 19.26 & $<0.001^{*}$ \\
\hline Total count (mg/dl) & 148.09 & 28.42 & 151.36 & 31.79 & 148.6 & 20.68 & 0.809 \\
\hline Triglycerides (mg/dl) & 118.9 & 48.44 & 122.05 & 73.02 & 141.16 & 53.38 & 0.322 \\
\hline $\operatorname{HDL}(\mathrm{mg} / \mathrm{dl})$ & 41.03 & 6.62 & 40.97 & 8.9 & 36.65 & 9.23 & 0.063 \\
\hline $\mathrm{LDL}(\mathrm{mg} / \mathrm{dl})$ & 84.33 & 24.66 & 86.09 & 27.44 & 83.83 & 17.89 & 0.897 \\
\hline VLDL (mg/dl) & 24.24 & 9.44 & 25.18 & 14.16 & 26.5 & 10.41 & 0.741 \\
\hline TG/HDL & 2.98 & 1.44 & 3.17 & 2.25 & 3.74 & 1.69 & 0.265 \\
\hline LDL/HDL & 2.14 & 0.64 & 2.15 & 0.7 & 2.42 & 0.75 & 0.203 \\
\hline Creatinine (mg/dl) & 0.53 & 0.14 & 0.53 & 0.17 & 0.54 & 0.2 & 0.959 \\
\hline $\mathrm{FBG}(\mathrm{mg} / \mathrm{dl})$ & 88.33 & 10.02 & 90.87 & 9.34 & 92.25 & 12.37 & 0.215 \\
\hline GTT 1 h (mg/dl) & 110.13 & 24.71 & 118.26 & 26.73 & 127.83 & 28.38 & $0.021 *$ \\
\hline GTT 2 h (mg/dl) & 104.59 & 13.1 & 110.35 & 20.3 & 111.71 & 21.57 & 0.144 \\
\hline Fasting insulin (uIU/ml) & 18.29 & 10.46 & 21.84 & 14.69 & 26.3 & 14.72 & $0.046^{*}$ \\
\hline HOMA-IR & 4.01 & 2.38 & 5.06 & 3.56 & 6.24 & 4.03 & $0.018^{*}$ \\
\hline HBA1c & 0.08 & 0.11 & 0.07 & 0.09 & 0.06 & 0 & 0.527 \\
\hline
\end{tabular}

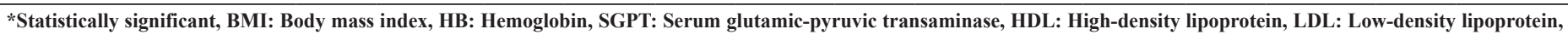

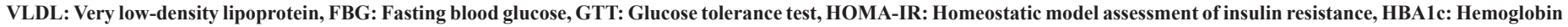
A1c or glycated hemoglobin 
Age and distribution of gender were similar in the two groups. Mean BMI, white cells (WCs), WHR, BP, SGPT, fasting insulin, HOMA-IR, and prevalence of acanthosis nigricans were higher in the adolescents with NASH compared to those without NASH. The anthropometric and biochemical parameters were further compared between the adolescents without NASH $(n=54)$, with mild NASH $(n=68)$, and with moderate or severe NASH $(n=24)$. The parameters that were significantly different among the adolescents in these three groups are presented in Table 3. A clear gradation of BMI, WC, acanthosis nigricans, SGPT, lipid profile, fasting insulin, and HOMA-IR was observed across the three groups, showing further the association between severity of obesity, insulin resistance, and NASH.

\section{DISCUSSION}

Childhood obesity is one of the primary predictors of obesity in adults. More than two-thirds of children with obesity will become obese adults [23]. NASH, metabolic syndrome, type 2 diabetes mellitus, obstructive sleep apnea, and cardiovascular disease are not only well-described complications of obesity in adults but are also becoming increasingly recognized conditions in children. Elevated serum aminotransferases activity gives evidence of inflammation and the death of hepatocytes [24].

Anderson et al. reported the prevalence of NAFLD in the general population as $7.8 \%$ and to surpass $30 \%$ in those who are obese [11]. In one more study done by Reetha et al. [25] showed that prevalence of NAFLD among obese children residing in North Kerala, to be $60 \%$ and $20 \%$ of these, had elevated level of alanine amino transferase. A total of 65 patients (age: 5-18 years) were enrolled in this annual study.

NASH can occur in very young children also, but it is more prevalent in adolescents. Factors responsible for higher rate of NASH in adolescents include the role of pubertal hormones, increasing obesity, unhealthy eating habits, and sedentary lifestyle. In the current study, majority of children were $>11$ years of age. Literature suggest that higher prevalence of NAFLD is associated with male gender, while estradiol affords some protection in females [26]. Our results showed occurrence of NASH slightly more in females (51.4\%).

Higher mean weight, BMI, waist circumference, and waisthip ratio were significantly associated with NASH in the present study, as observed in other studies [27,28]. The presence and severity of acanthosis nigricans were also observed to be significantly higher in the children with NASH compared to those without. In our present study, Acanthosis nigricans was observed to be significantly higher in children with NASH compared to those without NASH. Hence this was used as a clinical risk marker for complications of obesity.

A clear gradation of the observed clinical and biochemical variables (Table 3) across the three groups showed further association between severity of obesity, insulin resistance, and NASH. These results are similar to one Indian study by Vandana Jain et al. [29]. However, the study was conducted in a tertiary care center and serves as a referral center for childhood obesity.

\section{CONCLUSION}

There is a higher occurrence of NASH in obese and overweight children (63\%) as observed in USG findings and abnormal ALT. Hence, all overweight and obese children should be screened for $\mathrm{NASH}$, especially if one or more of the risk markers are present.

\section{REFERENCES}

1. Ranjani H, Mehreen TS, Pradeepa R, Anjana RM, Garg R, Anand K, et al. Epidemiology of childhood overweight and obesity in India: A systematic review. Indian J Med Res 2016;143:160-74.

2. Putri RR, Casswall T, Hagman E. Prevalence of increased transaminases and its association with sex, age, and metabolic parameters in children and adolescents with obesity-a nationwide cross-sectional cohort study. BMC Pediatr 2021;21:271.

3. Papachristodoulou A, Kavvadas D, Karamitsos A, Papamitsou T, Chatzidimitriou M, Sioga A. Diagnosis and staging of pediatric nonalcoholic fatty liver disease: Is classical ultrasound the answer? Pediatr Rep 2021;13:312-21.

4. di Sessa A, Umano GR, Miraglia Del Giudice E. The association between non-alcoholic fatty liver disease and cardiovascular risk in children. Children (Basel) 2017;4:57.

5. Flisiak-Jackiewicz M, Bobrus-Chociej A, Wasilewska N, Lebensztejn DM. From nonalcoholic fatty liver disease (NAFLD) to metabolic dysfunctionassociated fatty liver disease (MAFLD)-new terminology in pediatric patients as a step in good scientific direction? J Clin Med 2021;10:924.

6. Brambilla P, Bedogni G, Moreno LA, Goran MI, Gutin B, Fox KR, et al. Crossvalidation of anthropometry against magnetic resonance imaging for the assessment of visceral and subcutaneous adipose tissue in children. Int $\mathrm{J}$ Obes (Lond) 2006;30:23-30.

7. Mager DR, Yap J, Rodriguez-Dimitrescu C, Mazurak V, Ball G, Gilmour S. Anthropometric measures of visceral and subcutaneous fat are important in the determination of metabolic dysregulation in boys and girls at risk for nonalcoholic fatty liver disease. Nutr Clin Pract 2013;28:101-11.

8. Kitade H, Chen G, Ni Y, Ota T. Nonalcoholic fatty liver disease and insulin resistance: New insights and potential new treatments. Nutrients 2017;9:387.

9. Nobili V, Svegliati-Baroni G, Alisi A, Miele L, Valenti L, Vajro P. A 360-degree overview of paediatric NAFLD: Recent insights. J Hepatol 2013;58:1218-29.

10. Pawar SV, Zanwar VG, Choksey AS, Mohite AR, Jain SS, Surude RG, et al. Most overweight and obese Indian children have nonalcoholic fatty liver disease. Ann Hepatol 2016;15:853-61.

11. Anderson EL, Howe LD, Jones HE, Higgins JP, Lawlor DA, Fraser A. The prevalence of non-alcoholic fatty liver disease in children and adolescents: A systematic review and meta-analysis. PLoS One 2015;10:e0140908.

12. Volovelsky O, Weiss R. Fatty liver disease in obese children-relation to other metabolic risk factors. Int J Pediatr Obes 2011;6 Suppl 1:59-64.

13. Khadilkar A, Ekbote V, Chiplonkar S, Khadilkar V, Kajale N, Kulkarni S, et al. Waist circumference percentiles in 2-18 year old Indian children. J Pediatr 2014;164:1358-62.e2.

14. Qiao Q, Nyamdorj R. The optimal cutoff values and their performance of waist circumference and waist-to-hip ratio for diagnosing Type II diabetes. Eur J Clin Nutr 2010;64:23-9.

15. Lee JH, Jeong SJ. What is the appropriate strategy for diagnosing NAFLD using ultrasonography in obese children? World J Pediatr 2017;13:248-54.

16. Al-Hamad D, Raman V. Metabolic syndrome in children and adolescents. Transl Pediatr 2017;6:397-407.

17. Schwimmer JB, Dunn W, Norman GJ, Pardee PE, Middleton MS, Kerkar N, et al. SAFETY study: Alanine aminotransferase cutoff values are set too high for reliable detection of pediatric chronic liver disease. Gastroenterology 2010;138:1357-64, 1364.e1-2.

18. American Diabetes Association. Diagnosis and classification of diabetes mellitus. Diabetes Care 2014;37 Suppl 1:S81-90. 
19. Singh Y, Garg MK, Tandon N, Marwaha RK. A study of insulin resistance by HOMA-IR and its cut-off value to identify metabolic syndrome in urban Indian adolescents. J Clin Res Pediatr Endocrinol 2013;5:245-51.

20. Kelishadi R, Haghdoost AA, Moosazadeh M, Keikha M, Aliramezany M. A systematic review and meta-analysis on screening lipid disorders in the pediatric age group. J Res Med Sci 2015;20:1191-9.

21. Yamanaka AB, Davis JD, Wilkens LR, Hurwitz EL, Fialkowski MK, Deenik J, et al. Determination of child waist circumference cut points for metabolic risk based on acanthosis nigricans, the children's healthy living program. Prev Chronic Dis 2021;18:E64.

22. Gupta N, Jindal G, Nadda A, Bansal S, Gahukar S, Kumar A. Prevalence and risk factors for nonalcoholic fatty liver disease in obese children in rural Punjab, India. J Family Community Med 2020;27:103-8.

23. Piri Z, Barzin M, Mahdavi M, Guity K, Azizi F, Hosseinpanah F, et al. The role of childhood BMI in predicting early adulthood dysglycemia: Tehran lipid and glucose study. Nutr Metab Cardiovasc Dis 2020;30:313-9.

24. McGill MR. The past and present of serum aminotransferases and the future of liver injury biomarkers. EXCLI J 2016;15:817-28.

25. Reetha G, Mahesh P. Prevalence of non-alcoholic fatty liver disease among obese children in North Kerala, India. Int J Contemp Pediatr 2017;4:1051.
26. Peng L, Wu S, Zhou N, Zhu S, Liu Q, Li X. Clinical characteristics and risk factors of nonalcoholic fatty liver disease in children with obesity. BMC Pediatr 2021;21:122.

27. Kaltenbach TE, Graeter T, Oeztuerk S, Holzner D, Kratzer W, Wabitsch M, et al. Thyroid dysfunction and hepatic steatosis in overweight children and adolescents. Pediatr Obes 2017;12:67-74.

28. Boyraz M, Hatipoğlu N, Sarı E, Akçay A, Taşkın N, Ulucan K, Akçay T. Non-alcoholic fatty liver disease in obese children and the relationship between metabolic syndrome criteria. Obes Res Clin Pract 2014;8:e356-63.

29. Jain V, Jana M, Upadhyay B, Ahmad N, Jain O, Upadhyay AD, et al. Prevalence, clinical and biochemical correlates of non-alcoholic fatty liver disease in overweight adolescents. Indian J Med Res 2018;148:291-301.

Funding: None; Conflicts of Interest: None Stated.

How to cite this article: Patil S, Angadi K, Somasundara M. A study of occurrence of non-alcoholic steatohepatitis in children with obesity and overweight. Indian J Child Health. 2021; 8(9):314-318. 